Universities. The school teachers pay a subscription of 60 French francs $(\simeq 10$ U.S. $\$)$ a year (4 issues).

D. McNally: I recommend Les Cahiers Clairaut highly. Although they are written in French, they are written clearly, so that readers with a liminted knowledge of the French language can still understand.

\title{
AN EXAMPLE OF CLEA ACTIVITIES IN THE TRAINING OF SCHOOL TEACHERS
}

\author{
L. Bottinelli ${ }^{1,2}$, J. Dupré1 ${ }^{1}$ M. Gerbaldi ${ }^{1,3}$, L. Gouguenheim $^{1,2}$ \\ ${ }^{1}$ Astronomie, Bât. 470 Université Paris Sud, 91405 Orsay Cedex, France \\ ${ }^{2}$ Observatoire de Paris, Section de Meudon, 92195 Meudon, France \\ ${ }^{3}$ Institut d'Astrophysique, 98 bis Bd. Arago, 75014 Paris, France
}

Various simple activities are being developed by the French Comité de Liaison Enseignants Astronomes (CLEA) in the training of school teachers. We give in the following one example of a very simple instrument which we call "Alphonse's box," after Alphonse Delavergne who invented it. It is also called a heliograph. This very simple and inexpensive instrument enables (1) the plotting of the daily apparent path of the sun, (2) the determination of the duration of sunlight, and (3) the determination of the declination of the sun. The following description is due to Maryse Jonas:

\section{Material}

1. photosensitive paper (used by architects) that can be handled in semi-darkness; its sensitive face is yellow and it is developed by the vapor of an ordinary ammonia solution in about ten minutes;

2. a simple can, with a cover that will shut tight; approximate dimensions: diameter $10 \mathrm{~cm}$, height $15 \mathrm{~cm}$, with a hole about $0.5 \mathrm{~mm}$ in diameter on one side;

3. two pieces of wood, $15 \times 15 \mathrm{~cm}$ and $15 \times 20 \mathrm{~cm}$; one butt hinge; one threaded rod with two nuts and two washers.

\section{Orientation of the Box}

The first piece of wood is horizontal, and the second one is in the equatorial plane. The axis of the box is in the direction of the polar axis, so the angle $\alpha$ between 
the two pieces is $90^{\circ}$ - the latitude. The butt hinge allows the heliograph to be used at different latitudes. The cover of the box is fixed to the small equatorial board, and a plumb line, together with a protractor, enables the setting of the latitude (Fig. 1). The photosensitive paper must be placed inside the box (in semi-darkness) with the sensitive side exposed, using either magnets or Scotch tape to hold it in place. Its bottom edge must be flat against the bottom of the box. The $0.5 \mathrm{~mm}$ hole must not be covered by the paper. The box must be placed exactly on the meridian. This can be done at night, by observing the pole star through a thin tube put along the axis of the box. Figure 1 shows the assembly and orientation of the box, and Figure 2 shows the box assembled.

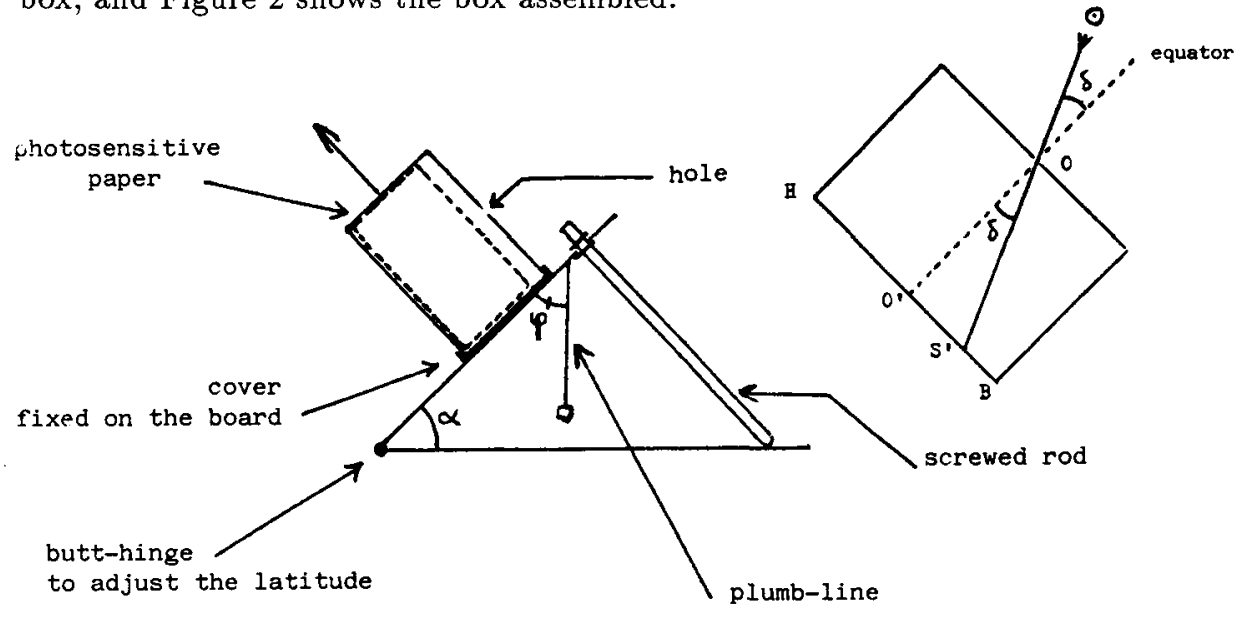

Fig. 1: The assembly and orientation of the heliograph.

\section{Use of the Recording}

Figure 3 shows the records obtained in different seasons. The general shape of the curve gives the sign of the declination of the sun. Noon (local solar time) is given by the straight-line tangent to the curve and parallel to the edge of the sheet. Note that this determination is not possible at the equinoxes. The time scale can be obtained by noting that the scale of the record is $\mathrm{R} \times 2 \theta$, where $\mathrm{R}$ is the radius of the box and $\theta$ is the angular velocity of the sun in the sky $\left(15^{\circ} /\right.$ hour $)$. From this, we can determine the duration of sunlight, the times when the sun was hidden by clouds, and the times of sunrise and sunset. The declination $\delta$ of the sun is also easily obtained (Fig. 1) by measuring, at noon, $\mathrm{O}^{\prime} \mathrm{S}^{\prime}=\mathrm{HS}^{\prime}-\mathrm{HO}^{\prime}$ and noting that $\tan \delta=\mathrm{O}^{\prime} \mathrm{S}^{\prime} / 2 \mathrm{R}$. Finally, the equation of time (observed solar time - mean solar time) can be obtained from the difference between the noon observed and noon, mean solar time. The heliograph must be placed in exactly the same place for one year, the hole being unmasked for only one minute each 15 days at the same civil time (noon, for example). 


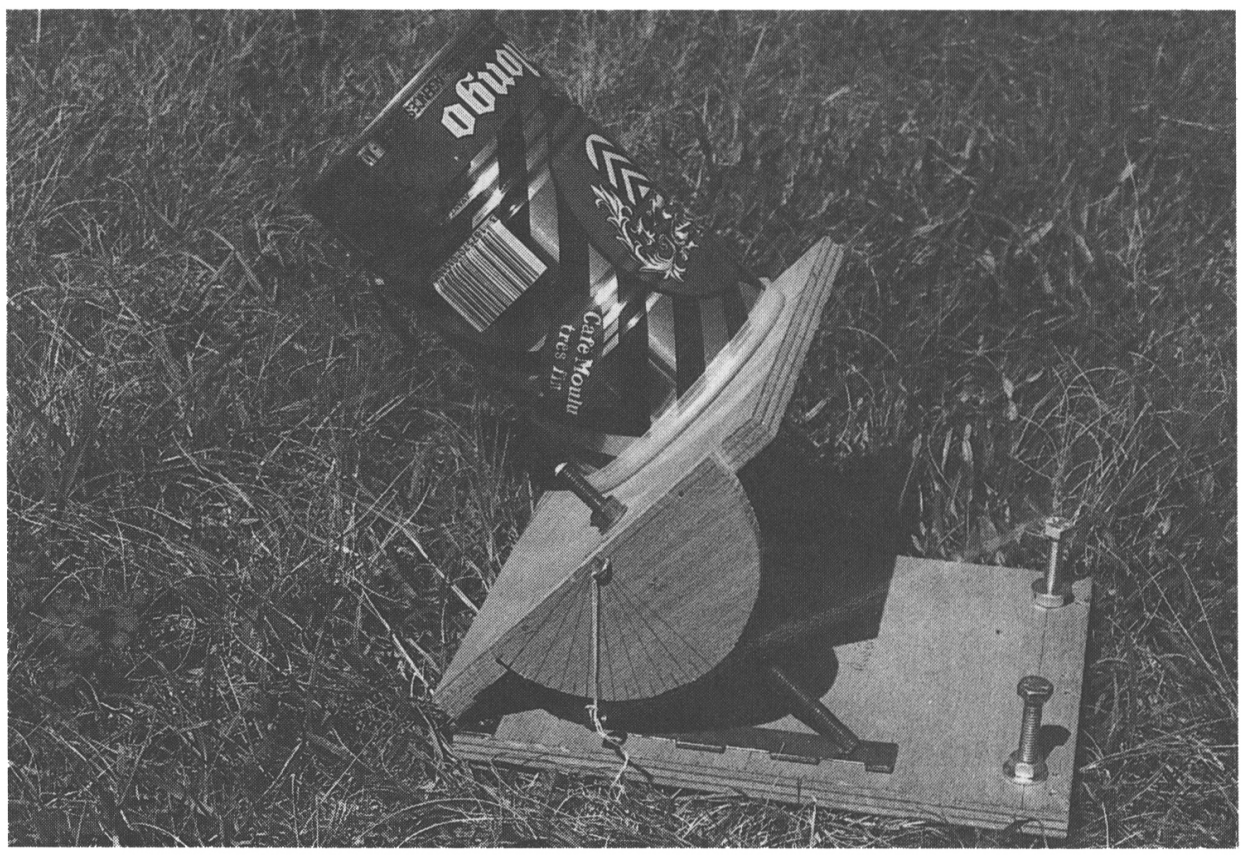

Fig. 2: A photograph of the heliograph assembled.

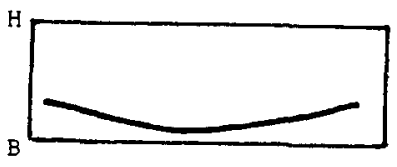

spring-summer

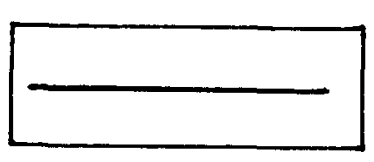

equinoxes

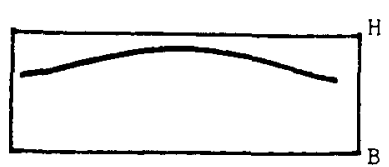

autumn-winter

Fig. 3: Different shapes of records obtained at different seasons. 